\title{
Less Invasive Bariatric/Metabolic Procedures for Weight Reduction and Glucose Control
}

\author{
Young Suk Park*, Sang-Hoon Ahn, Yun-Suhk Suh, Hyung-Ho Kim \\ Department of Surgery, Seoul National University Bundang Hospital, Seoul National University College of Medicine, Seongnam, Korea
}

The prevalence of obesity has increased steadily in Korea as well as worldwide, and bariatric surgery is the most powerful treatment modality for morbid obesity. However, fear of invasive procedures means most patients prefer less invasive procedures. New treatment modalities for obesity are emerging, but in Korea, only one traditional gastric balloon is approved by the government. Although it is difficult to introduce new techniques in Korea because of the high entry barrier presented by the country's national health insurance system, it is important for physicians and surgeons to be aware of new obesity treatment modalities.

Key words: Obesity, Bariatric surgery, Gastroplasty, Therapeutic embolization, Gastric balloon

\author{
Received March 3, 2020 \\ Reviewed March 22, 2020 \\ Accepted April 9, 2020 \\ *Corresponding author \\ Young Suk Park \\ (iD) \\ https://orcid.org/0000-0002-6352-9759 \\ Department of Surgery, Seoul National \\ University Bundang Hospital, Seoul \\ National University College of Medicine, \\ 82 Gumi-ro 173beon-gil, Bundang-gu, \\ Seongnam 13620, Korea \\ Tel: +82-31-787-7099 \\ E-mail: youngsukmd@gmail.com
}

\section{INTRODUCTION}

Bariatric and metabolic surgery has been covered by Korea's national insurance system since January 2019. As the number of bariatric and metabolic surgery cases continues to increase, many physicians and patients with obesity, as well as surgeons, are paying more attention to weight-loss surgery. The social stigma that morbid obesity is the individual's fault is also slowly weakening. Because of the high entry barrier posed by the national health insurance system, it is difficult to introduce new obesity treatment techniques in Korea. Bariatric surgery has been accepted as an important treatment modality for severe obesity since the late 2000s, and the methodology in less invasive procedures has also been evolving, making it necessary patients and physicians to be aware of new treatment modalities (Table 1).

\section{PROCEDURELESS INTRAGASTRIC}

\section{BALLOONS}

Intragastric balloons are gastric volume-occupying devices that help satiate patients' hunger. A commercial intragastric balloon available in Korea is administered widely in local clinics. Intragastric balloons are usually placed endoscopically and can be filled with 400 to $800 \mathrm{~mL}$ of saline. The Elipse (Allurion Technologies, Wellesley, MA, USA) is designed to be swallowed and inflated through a catheter without endoscopy. This balloon is filled with $550 \mathrm{~mL}$ of saline through a connected catheter that is then removed via the mouth. The Ellipse spontaneously empties the saline through a release valve approximately 3 months later and it is excreted with the stool. A pilot study demonstrated that the weightloss effect of this procedureless gastric balloon was similar to that of an endoscopically placed balloon. ${ }^{1}$ However, it is possible to regain

Copyright (C) 2020 Korean Society for the Study of Obesity

(a) This is an Open Access article distributed under the terms of the Creative Commons Attribution Non-Commercial License (https://creativecommons.org/licenses/by-nc/4.o/) which permits unrestricted non-commercial use, distribution, and reproduction in any medium, provided the original work is properly cited. 
Table 1. Pros and cons of each procedure

\begin{tabular}{|c|c|c|c|}
\hline Procedure & Weight loss/glucose control & Pros & Cons \\
\hline $\begin{array}{l}\text { Procedureless intragastric } \\
\text { balloon }^{2}\end{array}$ & Percentage total weight loss, $10.9 \%$ at 6 months & $\begin{array}{l}\text { Swallowable balloon and spontaneous } \\
\text { removal }\end{array}$ & $\begin{array}{l}\text { Questionable result of weight maintenance } \\
\text { after balloon removal }\end{array}$ \\
\hline $\begin{array}{l}\text { Duodenal mucosal } \\
\text { resurfacing }\end{array}$ & $\begin{array}{l}\text { Weight loss, }-2.5 \mathrm{~kg} \text { at } 6 \text { months } / \mathrm{HbA} 1 \mathrm{c} \text { reduction, } 0.9 \% \\
\text { \& fasting glucose reduction, } 30.6 \mathrm{mg} / \mathrm{dL} \text { at } 6 \text { months }\end{array}$ & Superior glucose control effect & $\begin{array}{l}\text { Less weight loss } \\
\text { Duodenal stenosis reported }\end{array}$ \\
\hline $\begin{array}{l}\text { Endoscopic sleeve } \\
\text { gastroplasty }^{5-7}\end{array}$ & $\begin{array}{l}\text { Percentage total weight loss, } 14.9 \%-19.5 \% \text { at } 6 \text { months } \\
\text { and } 21.3 \% \text { at } 12 \text { months }\end{array}$ & Favorable weight loss results & $\begin{array}{l}\text { Difficulty in early diagnosis of gastric cancer } \\
\text { after endoscopic gastroplasty }\end{array}$ \\
\hline $\begin{array}{l}\text { Percutaneous endoscopic } \\
\text { gastrostomy tube }{ }^{8,9}\end{array}$ & Percentage total weight loss, $12.1 \%-18.2 \%$ at 12 months & No limit to eating & Persistent fistula reported \\
\hline Bariatric embolization ${ }^{10,11}$ & $\begin{array}{l}\text { Percentage excess weight loss, } 12.8 \% \text { at } 6 \text { months, and } \\
11.5 \% \text { at } 12 \text { months }\end{array}$ & $\begin{array}{l}\text { No need to import new equipment or } \\
\text { seek domestic approval }\end{array}$ & $\begin{array}{l}\text { Reduced vascularity of stomach after } \\
\text { embolization }\end{array}$ \\
\hline
\end{tabular}

HbA1c, glycosylated hemoglobin.

weight after the intragastric balloon is removed, and the long-term effects have not been fully demonstrated. Recently, a prospective single-arm trial showed favorable 1-year weight-reduction results with the use of a procedureless gastric balloon. ${ }^{2}$ However, weight regain was observed 6 months after balloon removal, and longerterm results should be evaluated in the future.

\section{DUODENAL MUCOSAL RESURFACING}

Bariatric surgery is an effective option for controlling blood sugar levels, especially in patients with obesity and type 2 diabetes mellitus (T2DM), hence the name bariatric and metabolic surgery rather than weight-reduction surgery. Many weight-reduction-independent mechanisms are available for diabetes control in bariatric surgery. The foregut and hindgut theories are traditional explanations for the metabolic effects of bariatric surgery. The foregut theory posits that excluding the presentation of nutrients to the duodenum and proximal jejunum contributes to improvement in glycemic regulation after bariatric surgery. ${ }^{12}$ Duodenal mucosal resurfacing (DMR) is an endoscopic intervention using specially designed catheters. It induces circumferential hydrothermal ablation of the duodenal mucosa and subsequent mucosal healing, resulting in an effect similar to foregut exclusion (Fig. 1). ${ }^{3}$ Investigators have conducted a prospective multicenter trial to evaluate the glycemic-control effect of DMR in people with T2DM $(n=46){ }^{4}$ In this trial, reductions of glycosylated hemoglobin of $0.9 \% \pm 0.2 \%$ were observed at 6 months compared with baseline values and this effect was preserved for up to 1 year. Fasting plasma glucose was reduced by $30.6 \pm 9.0 \mathrm{mg} / \mathrm{dL}$ and $32.4 \pm 9.0 \mathrm{mg} / \mathrm{dL}$ at 6 months and 12 months after DMR, re-

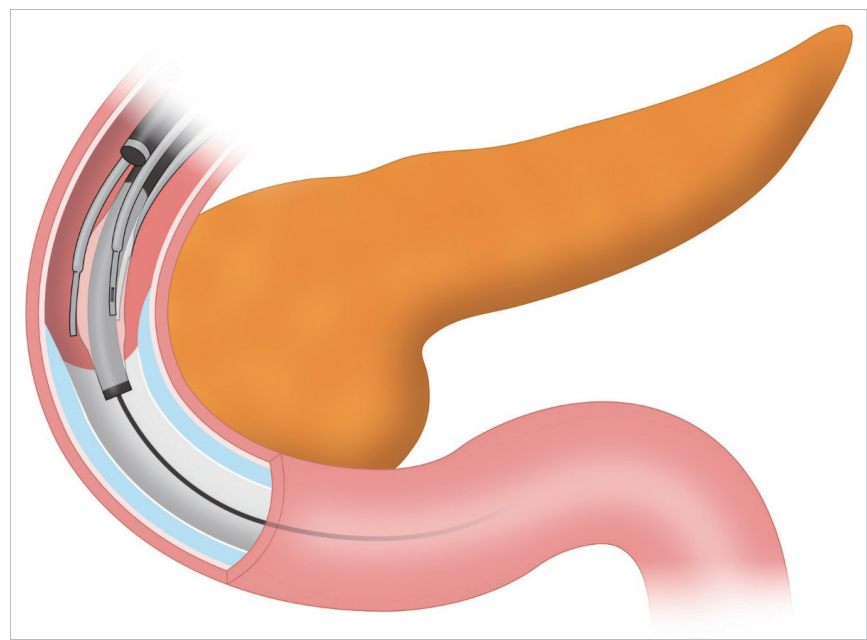

Figure 1. Schematic diagram of duodenal mucosal resurfacing. Circumferential ablation of the duodenal mucosa resulting in an effect similar to duodenal exclusion.

spectively.

\section{ENDOSCOPIC SLEEVE GASTROPLASTY}

Endoscopic sleeve gastroplasty (ESG) is a volume-reduction procedure using endoscopic intragastric suturing to create multiple tissue plication in the stomach and reduce the stomach lumen (Fig. 2). Two prospective multicenter clinical trials reported total body weight loss of $15.2 \%$ and $14.9 \%$ at 6 months after ESG. ${ }^{5,6}$ Serious adverse events, including perigastric fluid collection, extra- and intra-gastric hemorrhage, pulmonary embolism, pneumoperitoneum, and pneumothorax occurred in $2 \%-2.7 \%$ of study participants. All cases recovered without surgical intervention. Recently, Fayad et al. ${ }^{7}$ published a retrospective single-center study comparing 1-year results 

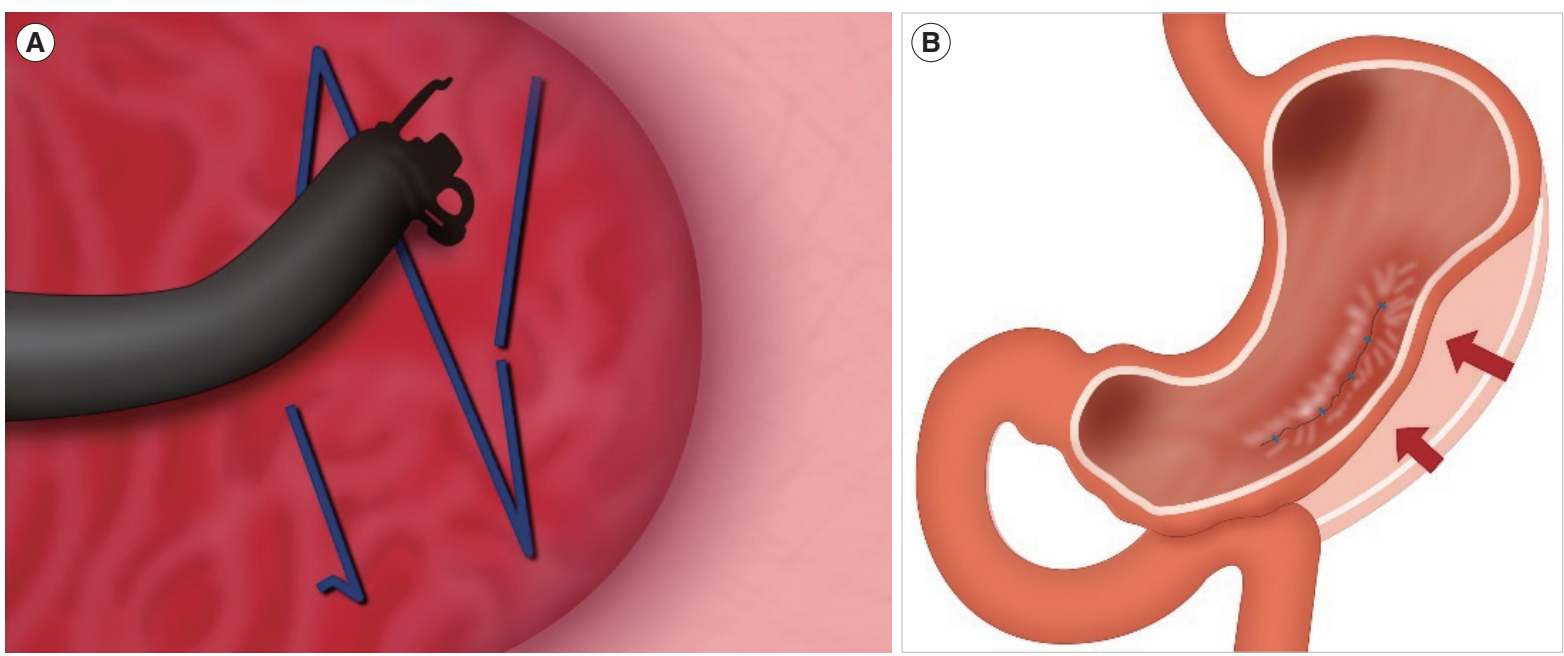

Figure 2. Procedures of endoscopic sleeve gastroplasty. (A) Endoscopic view: endoscopic suturing device. (B) Overall appearance: gastric volume reduction.

of ESGs and intragastric balloons. ESG demonstrated a superior weight-reduction outcome ( $21.3 \%$ vs. $13.9 \%$ at 1 year) and a lower complication rate ( $5.2 \%$ vs. $17 \%)$ compared with intragastric balloons during the year after intervention.

\section{PERCUTANEOUS ENDOSCOPIC GASTROSTOMY TUBES}

Aspiration therapy uses a percutaneous gastrostomy tube to partially drain the gastric contents after a meal (Fig. 3). The aspiration process involves flushing food out of the stomach through the tube and infusing water into the stomach and then reversing the flow to allow the remaining gastric contents to drain out of the stomach. This technique is reminiscent of the habits of Roman nobility, who were said to chew and spit without swallowing food in order to enjoy large meals. The effectiveness of the procedure has been verified in a pilot study, ${ }^{13}$ a randomized controlled trial, ${ }^{8}$ and a 4-year observational study. ${ }^{9}$ However, the proportion of patients on longterm maintenance of the device was low, and the longer a patient maintained the device, the greater the chance of persistent fistulas. These shortcomings represent obstacles to popularization of aspiration therapy.

\section{BARIATRIC EMBOLIZATION}

Transarterial embolization of the left gastric artery was designed

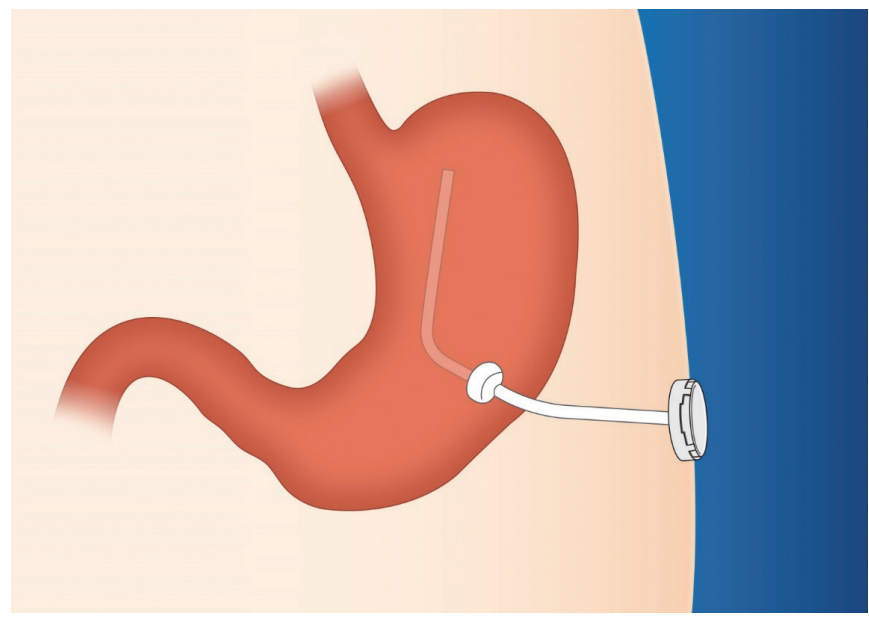

Figure 3. Percutaneous endoscopic gastrostomy tube. Endoscopically placed gastrostomy tube and skin port.

to reduce ghrelin secretion and the sense of hunger by altering the endocrine function of the gastric fundus..$^{10}$ Bariatric embolization produced a significant weight loss effect that lasted for 1 year in a prospective trial (mean excess weight loss $12.8 \%$ at 6 months and $11.5 \%$ at 12 months). ${ }^{11}$ Evidence for the precise mechanism of this therapy is still lacking, but the effect is reliable. One drawback of bariatric embolization is that reduced vascularity from left gastric artery embolization can cause ischemia of the remnant stomach, which could be an issue if bariatric surgery is performed to non-responders of this therapy. 


\section{CONCLUSION}

Four procedures, excluding bariatric embolization, require not only importing equipment into Korea but also government approval. It is unknown whether the techniques can be used in the near future in Korea because it is not easy for domestic companies to import such products into the country's relatively small market. On the other hand, bariatric embolization does not require any new products. It can be used for research purposes if the researcher obtains the approval of the institutional review board (Table 1). Although new methods for the treatment of obesity are difficult to develop or import to small markets, all researchers and clinicians should be apprised of the new methods and continue to consider which techniques are practical.

\section{CONFLICTS OF INTEREST}

The authors declare no conflict of interest.

\section{AUTHOR CONTRIBUTIONS}

Drafting of the manuscript: YSP; critical revision of the manuscript: SHA, and study supervision: YSS and HHK.

\section{REFERENCES}

1. Machytka E, Gaur S, Chuttani R, Bojkova M, Kupka T, Buzga $\mathrm{M}$, et al. Elipse, the first procedureless gastric balloon for weight loss: a prospective, observational, open-label, multicenter study. Endoscopy 2017;49:154-60.

2. Jamal MH, Almutairi R, Elabd R, AlSabah SK, Alqattan H, Altaweel T. The safety and efficacy of procedureless gastric balloon: a study examining the effect of elipse intragastric balloon safety, short and medium term effects on weight loss with 1-year follow-up post-removal. Obes Surg 2019;29:1236-41.

3. Rajagopalan H, Cherrington AD, Thompson CC, Kaplan LM, Rubino F, Mingrone G, et al. Endoscopic duodenal mucosal resurfacing for the treatment of type 2 diabetes: 6-month interim analysis from the first-in-human proof-of-concept study. Diabetes Care 2016;39:2254-61.
4. van Baar AC, Holleman F, Crenier L, Haidry R, Magee C, Hopkins D, et al. Endoscopic duodenal mucosal resurfacing for the treatment of type 2 diabetes mellitus: one year results from the first international, open-label, prospective, multicentre study. Gut 2020;69:295-303.

5. Lopez-Nava G, Sharaiha RZ, Vargas EJ, Bazerbachi F, Manoel GN, Bautista-Castaño I, et al. Endoscopic sleeve gastroplasty for obesity: a multicenter study of 248 patients with 24 months follow-up. Obes Surg 2017;27:2649-55.

6. Sartoretto A, Sui Z, Hill C, Dunlap M, Rivera AR, Khashab MA, et al. Endoscopic sleeve gastroplasty (ESG) is a reproducible and effective endoscopic bariatric therapy suitable for widespread clinical adoption: a large, international multicenter study. Obes Surg 2018;28:1812-21.

7. Fayad L, Cheskin LJ, Adam A, Badurdeen DS, Hill C, Agnihotri $\mathrm{A}$, et al. Endoscopic sleeve gastroplasty versus intragastric balloon insertion: efficacy, durability, and safety. Endoscopy 2019; 51:532-9.

8. Thompson CC, Abu Dayyeh BK, Kushner R, Sullivan S, Schorr $\mathrm{AB}$, Amaro A, et al. Percutaneous gastrostomy device for the treatment of class II and class III obesity: results of a randomized controlled trial. Am J Gastroenterol 2017;112:447-57.

9. Nyström M, Machytka E, Norén E, Testoni PA, Janssen I, Turró Homedes J, et al. Aspiration therapy as a tool to treat obesity: 1- to 4-year results in a 201-patient multi-center postmarket European registry study. Obes Surg 2018;28:1860-8.

10. Weiss CR, Akinwande O, Paudel K, Cheskin LJ, Holly B, Hong $\mathrm{K}$, et al. Clinical safety of bariatric arterial embolization: preliminary results of the BEAT obesity trial. Radiology 2017; 283:598-608.

11. Weiss CR, Abiola GO, Fischman AM, Cheskin LJ, Vairavamurthy J, Holly BP, et al. Bariatric Embolization of Arteries for the Treatment of Obesity (BEAT Obesity) trial: results at 1 year. Radiology 2019;291:792-800.

12. Cho YM. Mechanism of weight loss and diabetes remission after bariatric/metabolic surgery. Korean J Med 2013;84:629-39.

13. Sullivan S, Stein R, Jonnalagadda S, Mullady D, Edmundowicz S. Aspiration therapy leads to weight loss in obese subjects: a pilot study. Gastroenterology 2013;145:1245-52.e1-5. 